\title{
ATTRACTION TO PHEROMONE SOURCES OF DIFFERENT QUANTITY, QUALITY, AND SPACING: Density-Regulation Mechanisms in Bark Beetle Ips typographus ${ }^{1,2}$
}

\author{
FREDRIK SCHLYTER, JOHN A. BYERS, and JAN LÖFQVIST \\ Department of Animal Ecology \\ Lund University, Ecology Building \\ S-223 62 Lund, Sweden
}

(Received February 18, 1986; accepted September 10, 1986)

\begin{abstract}
The density of bark-beetle colonization of a tree could be regulated by a quantitative effect of the pheromone signal from beetles in the tree (cessation of release of attractive pheromone) or by a qualitative effect (production of pheromone components inhibiting attraction). The quantitative hypothesis was tested on Ips typographus by varying the release rate of the two known attractive compounds, 2-methyl-3-buten-2-ol (MB) and (4S)-cis-verbenol $(\mathrm{cV})$. The highest number of beetles were captured at traps with the highest release rates. The catch was nearly proportional to the release of $\mathrm{MB}$ and $\mathrm{cV}$ at a distance between traps of $12 \mathrm{~m}$ or more. At 6-, 3-, and $1.5-\mathrm{m}$ distances between traps deployed in a triangular arrangement there was still a good discrimination between release rates, but relatively more beetles, especially males, were caught on the blank. The lower release rates caught an equal sex ratio while the highest release rate caught only about $30 \%$ males. The qualitative hypothesis was tested by releasing the suspected inhibitors ipsdienol (Id) and ipsenol (Ie), from traps in the same amounts as cV. Only small effects were noted for $I$. typographus. However, the competitor $I$. $d u$ plicatus was attracted to Id and inhibited by le, while the predator Thanasimus formicarius was attracted to both compounds. On the other hand, when the ratio of Id or Ie to $\mathrm{cV}$ was $10: 1$ or $0.1: 1$ rather than $1: 1$, they affected the numbers of I. typographus attracted. A small amount of Id combined with the attractants increased trap catch, while large amounts of Id or Ie decreased attraction, especially when combined. Attack density regulation is modeled as an effect of both quantitative and qualitative mechanisms acting in sequence.
\end{abstract}

\footnotetext{
${ }^{1}$ Coleoptera: Scolytidae.
}

${ }^{2}$ This study was made within the Swedish project "Odour Signals for Control of Pest Insects." 
Key Words-2-methyl-3-buten-2-ol, cis-verbenol, ipsdienol, ipsenol, sex ratio, attraction, inhibition, Ips duplicatus, Thanasimus, switching, Ips typographus, Coleoptera, Scolytidae, Ceeridae.

\section{INTRODUCTION}

Regulation of colonization density is a crucial factor in the population biology of the spruce bark beetle, Ips typographus (L.). At high population levels the beetle is able to reach attack densities sufficient to overcome the resistance of a healthy tree by a mass attack involving several thousand beetles and governed by aggregation pheromones (Thalenhorst, 1958; Bakke and Riege, 1982). However, the high densities found on trees killed by mass attacks, 3-15 egg galleries $/ 100 \mathrm{~cm}^{2}$ (Thalenhorst, 1958; Lekander, 1972; Anderbrant, 1986), are often at a level where severe larval competition results in a low number and quality of offspring per female (Botterweg, 1983; Anderbrant et al., 1985). Consequently, the bark bettle needs not only a pheromone mechanism to initiate a mass attack to reach a sufficient attack density, but natural selection would also promote a system telling arriving individuals that a patch is occupied (Alcock, 1982). Arriving beetles may then colonize nearby patches, such as other parts of the tree or adjacent trees. Such "switching," where the attack first focuses on one tree but, in a few days, switches to other trees in the vicinity, has frequently been observed at high "epidemic" population densities both in Dendroctonus frontalis (Coulson, 1979), D. ponderosae (Geiszler et al., 1980), and in I. typographus (J.M. Hoff, unpublished; O. Anderbrant et al., unpublished).

Little is known about variation in pheromone production and response in bark beetles during the colonization phases and how pheromones may be used in regulation of density (Byers et al., 1984). Byers (1983) suggested that colonization density in Ips paraconfusus Lanier along the trunk of a felled tree was regulated in part by sex-specific responses to quantitative changes in the rate of pheromone release. Males appeared to avoid higher pheromone concentrations emanating from the densely colonized patches and thus settle in adjacent areas where their pheromone production spreads the area of aggregation and colonization. Schlyter and Löfqvist (1986) showed in the laboratory that walking $I$. typographus females were more attracted to stronger sources of natural pheromone than were walking males. 2-Methyl-3-buten-2-ol (MB) and (4S)-cis-verbenol $(\mathrm{cV})$ are the essential components of the aggregation pheromone of $I$. typographus (Bakke and Riege, 1982; Schlyter et al., 1987b). The quantity of these two compounds in hindguts is maximal when the unmated male constructs his nuptial chamber under the bark (Birgersson et al., 1984). Later, when the males are mated and females are laying eggs, $\mathrm{MB}$ and $\mathrm{cV}$ decrease substantially, while ipsdienol (Id) and ipsenol (Ie) reach the same order of magnitude as cV. Id has been indicated as a synergist (Bakke et al., 1977) and le as an inhibitor (Bakke, 1981) of the aggregation pheromone. 
In I. typographus, regulation of density and tree-switching by pheromone could then be hypothesized to take place by one or both of the following mechanisms:

1. Quantitative Hypothesis. Initially, males attack in relation to the amount of attractant odor. As the release increases, some of the males attracted to the initial attack site are deflected by high concentrations of pheromone when they reach the source and so attack patches (adjacent bark areas or trees) a short distance away. After mating, the males in the first patch produces less attractant, and the aggregation would switch to the newly attacked areas.

2. Qualitative Hypothesis. The higher amounts of inhibitors such as Id and le released in the later phases by the earliest arriving males cause an inhibition of attraction, especially in males. Surrounding areas would receive the new attacks and the colonization activity would switch.

From the quantitative hypothesis follows at least two predictions: First, beetles should discriminate between sources of different release rate, and males, compared to females, should be relatively less attracted to the highest rates. Second, discrimination should be significant even when sources are only a few meters apart (as are mature trees in a forest).

From the second, qualitative hypothesis, it follows that the presence of Id and Ie should, especially at the higher release rates or ratios, lower the number of beetles attracted.

In order to test these hypotheses, we have in the field studied beetles landing on sticky traps deployed in triangular arrays at four spacings with three release rates of $\mathrm{MB}$ and $\mathrm{cV}$. We have also studied the attraction to pipe traps at constant spacings baited with a concentration range of attractants (MB and $\mathrm{cV}$ ) with and without Id or Ie, or both, in different proportions.

\section{METHODS AND MATERIALS}

Synthetic Substances, Dispensers, and Release Rates. The synthetic substances were released from polyethylene (PE) vials with different sizes of openings (MB, cV, and high rates of Id and Ie) or from glass capillaries (low rates of Id and Ie). Release rates from PE vials were determined from weight loss in a mini wind tunnel, $0.70 \mathrm{~m} / \mathrm{sec}$, at $20^{\circ} \mathrm{C}$. Weights were taken on a balance to the nearest microgram and corrected for weight changes of empty control vials. The slope with its $95 \%$ confidence interval of the regression of weight $(y)$ on time $(x)$ gave the estimated release rate, Table 1 . The release rates of Id and Ie from capillaries were measured in a similar wind tunnel. The capillaries were $12 \mathrm{~mm}$ long, fused at one end, and filled from the bottom through an inserted thin capillary (Löfqvist, unpublished). The loss of liquid from the capillaries was measured by the change of the position of the meniscus under a stereomicroscope.

$\mathrm{MB}$ and $\mathrm{cV}$ were released in the field experiments at three release rates 
each at a ratio of about $50: 1$, which is close to or larger than that found in male hindguts (Birgersson et al., 1984). The lowest release rate of $\mathrm{cV}$ was somewhat higher (about $0.03 \mathrm{mg} /$ day) than intended $(0.01)$ and the medium was lower $(0.052 \mathrm{mg} /$ day $)$ than intended $(0.10)$. This altered the target MB-cV ratio somewhat as MB was released at evenly spaced decadic steps. However, the ratio of $\mathrm{MB}$ to $\mathrm{cV}$ changes the sex ratio very little and it is the MB release that is the most critical in determining the total number caught (Schlyter et al., 1987a). The highest rate, $50 \mathrm{mg} \mathrm{MB}$ and $1 \mathrm{mg} \mathrm{cV}$ per day, corresponds to the release from $1 \mathrm{~m}$ of commercial Borregaard/Hercon Ipslure ${ }^{\circledR}$ dispenser, aged one week (Schlyter et al., 1987b).

Triangle Experiment: Variation of Pheromone Release Rate and Spacing. Three traps arranged in an equilateral triangle constituted a trap group. Each group had a blank trap and various combinations of two of the three possible decadic release rates of $\mathrm{MB}$ and $\mathrm{cV}$ (Tables 1 and 2). Randomization between replicates took place only within groups, as it was impractical to change the positions of whole trap groups. This means that comparisons of absolute catches between groups are not valid. However, comparisons can be made between groups based on relative catches within a group.

The chemical dispensers were housed in $30-\mathrm{cm}$ sections of commercial drain pipe traps, suspended on 1.5 -m-long steel pipes. The black dispenser housing was surrounded by a tubular sticky trap $(31 \times 19 \mathrm{~cm}$ diam. $)$ of No. 4 hardware cloth coated with Stikem Special ${ }^{\circledR}$.

For the first trapping period (six replicates between the days May 16 and 31 , the traps were spaced at 3-, 6-, and 12-m distances in nine trap groups (three baitings $\times$ three spacings) (Figure 1). Since the blank caught few beetles even in groups with 3-m spacing, we decided to arrange all nine trap groups in a $1.5-\mathrm{m}$ spacing distance for a second trapping period (eleven replicates between May 31 and June 12, 1982).

The test area was in a clear-cut at $160 \mathrm{~m}$ altitude, near Torsby, province of Värmland, Sweden, with a moderately high beetle population (more than 100 trees killed the previous year within $0.7 \mathrm{~km}$ ). The trap groups were placed in a grid with equal distance between groups $(50 \mathrm{~m})$ on a gentle west slope (maximum elevation difference was $20 \mathrm{~m}$ ).

Quantitatively and Qualitatively Different Baits at Constant Spacings. In the 1982 test, four qualitative combinations of either Id or Ie, both, or neither were released with three rates of $\mathrm{MB}$ and $\mathrm{cV}$ yielding 12 different baits (Tables 3 and 4). The release rate of Id and Ie was varied to correspond approximately with that of $\mathrm{cV}$.

Black pipe traps with a white funnel at the base ("N 79 with funnel" in Regnander and Solbreck, 1981) were used at a spacing of about $50 \mathrm{~m}$. Treatment (trap with a bait) positions were randomized after each replicate. The Ie in PE vials was replaced after the first replicate as it began to polymerize.

One set of 12 traps was used in each of two widely separated sites near 


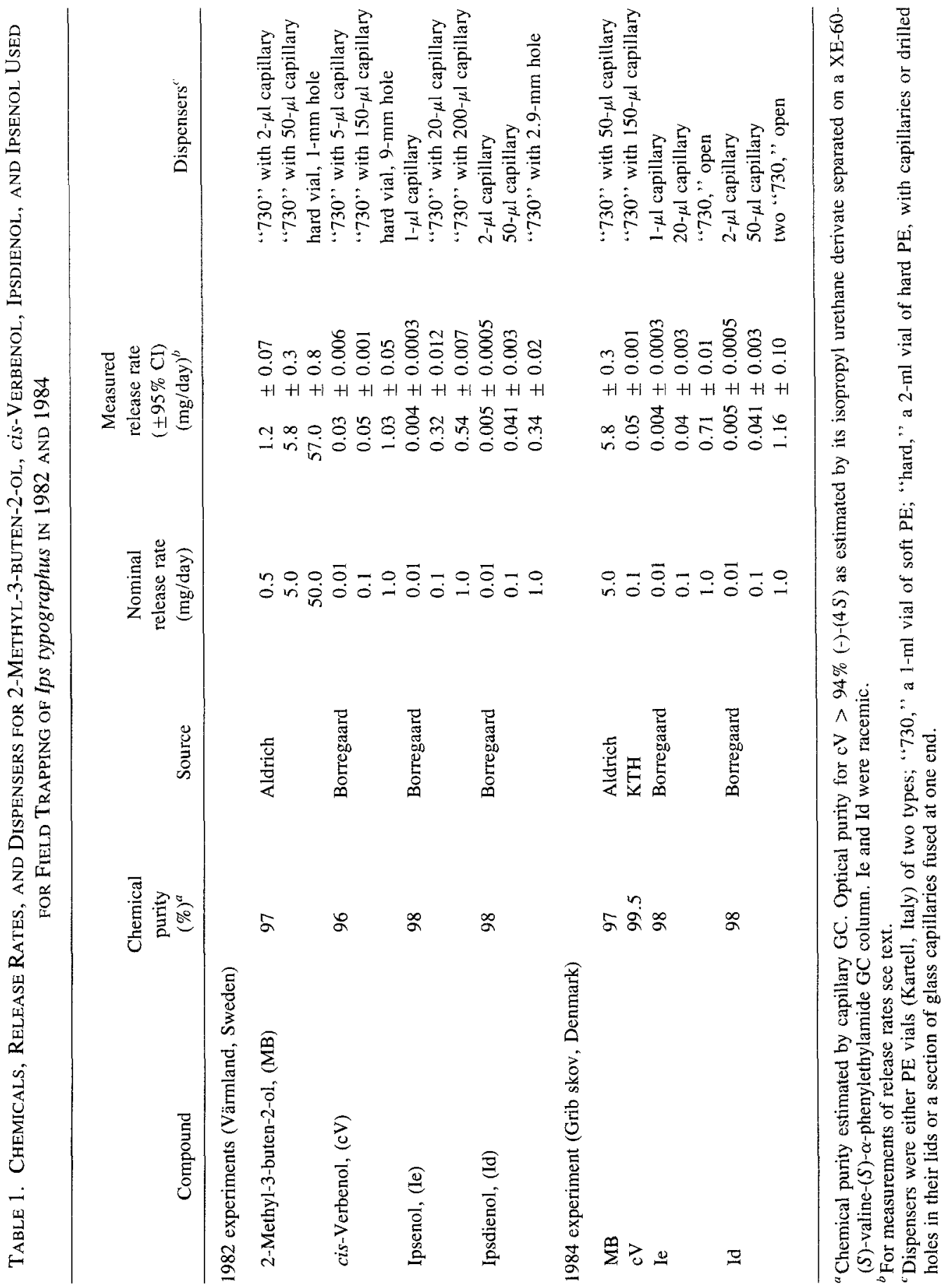




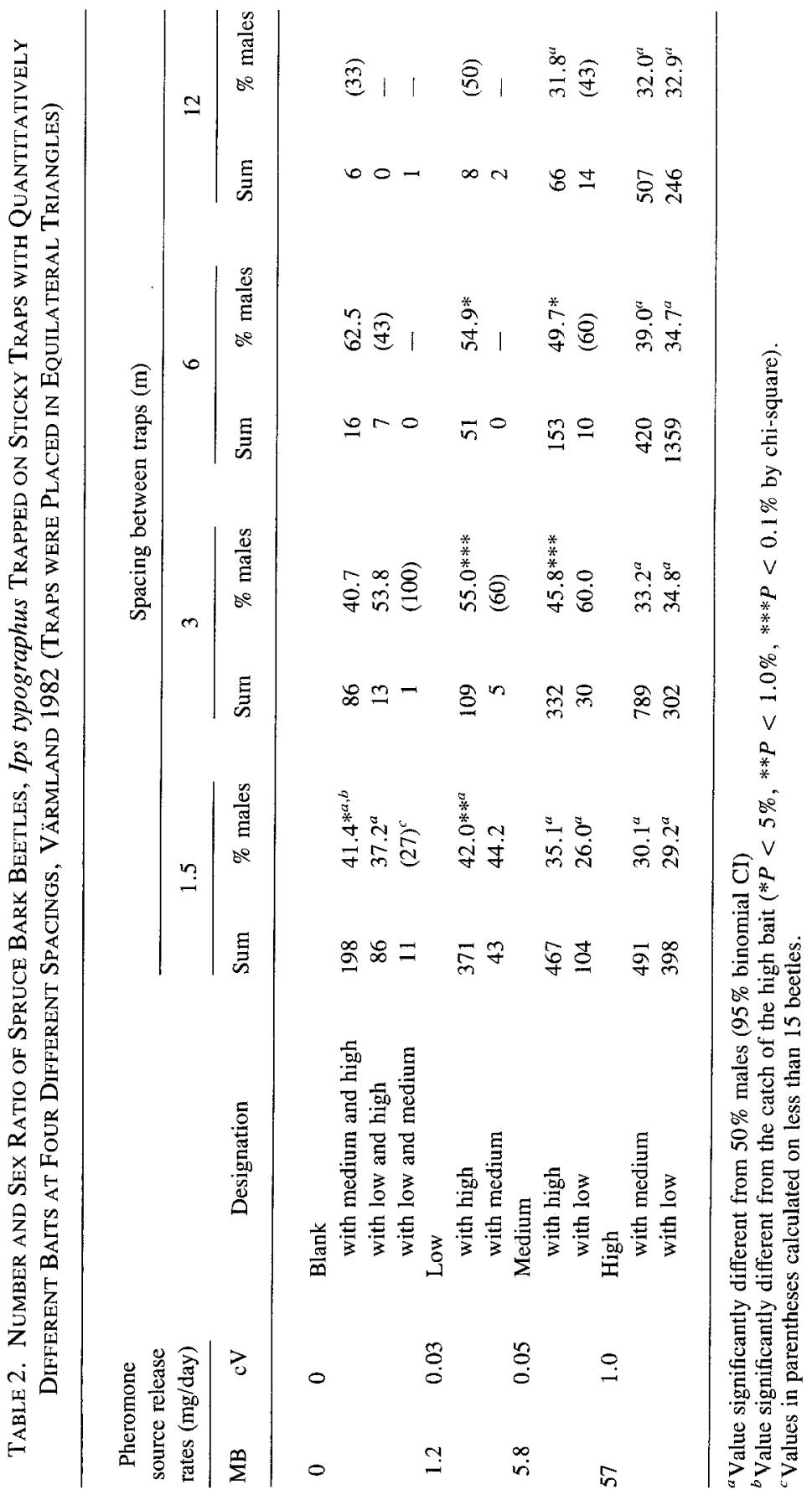



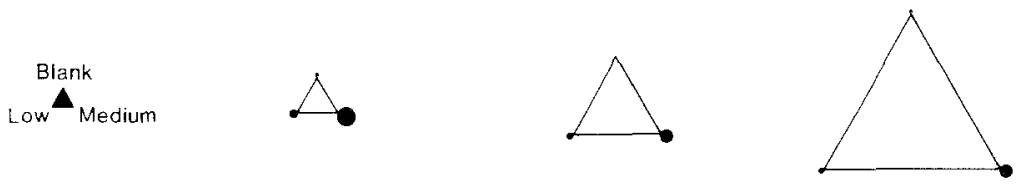

$\stackrel{\text { Blank }}{\text { Low }}$
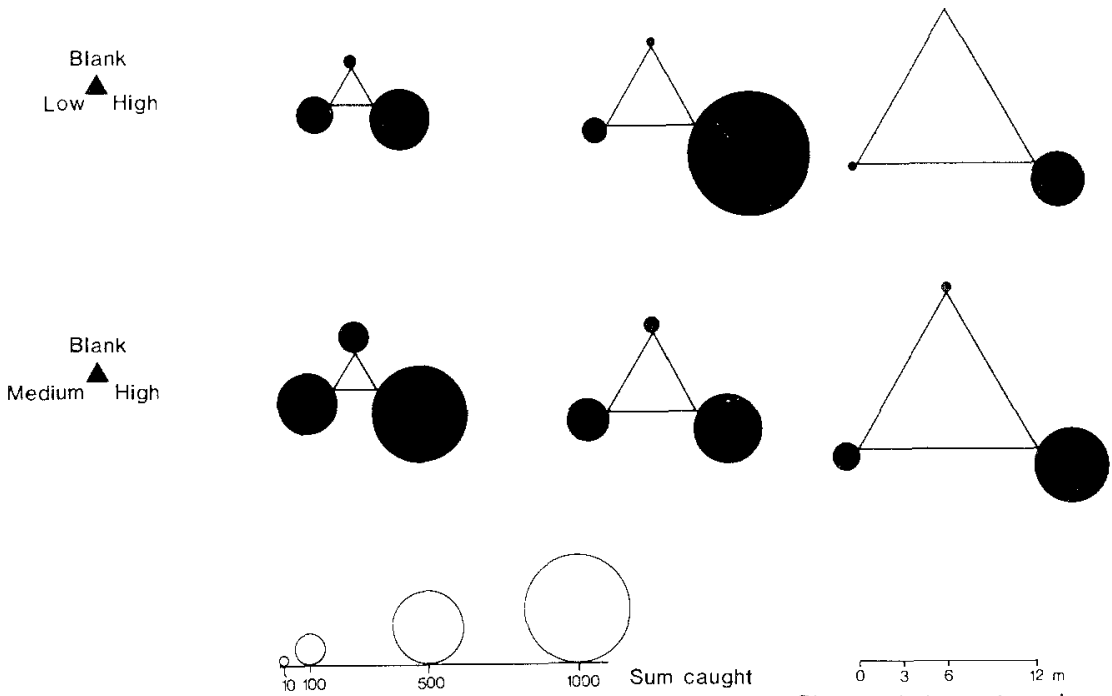

Distance between traps in group

FIG. 1. Total catch on sticky traps with quantitatively different baits at different spacings within triangle trap groups during the first trapping period. Catch data from the $1.5-\mathrm{m}$ spacing during the second period and release rates of baits are shown in Table 2 . The different baits are indicated at the black triangles at left. Baits were randomized within trap groups and distance between trap groups was $50 \mathrm{~m}$.

Torsby, province of Värmland, Sweden. Site L, a 3-year-old clear-cut area at $145 \mathrm{~m}$ altitude, had a low local beetle population, with no standing trees attacked the previous year within $0.5 \mathrm{~km}$. Site $\mathrm{T}$, a fresh clear-cut at $105 \mathrm{~m}$ altitude, had a high local population because many standing trees were killed within the cutting area the previous year, so that a high density of beetles were probably wintering in the duff close to the traps. Trapping was done between May 16 and June 9, 1982.

In the 1984 test, nine combinations of $\mathrm{Id} / \mathrm{Ie}$, with $\mathrm{MB}+\mathrm{cV}$ at a constant medium dose, as well as $\mathrm{MB}+\mathrm{cV}$ alone as a control (ten different baits) were tested (Table 5).

$\mathrm{MB}$ and $\mathrm{cV}$ were released with the same type of dispensers as used for the medium release rate in the 1982 test. 


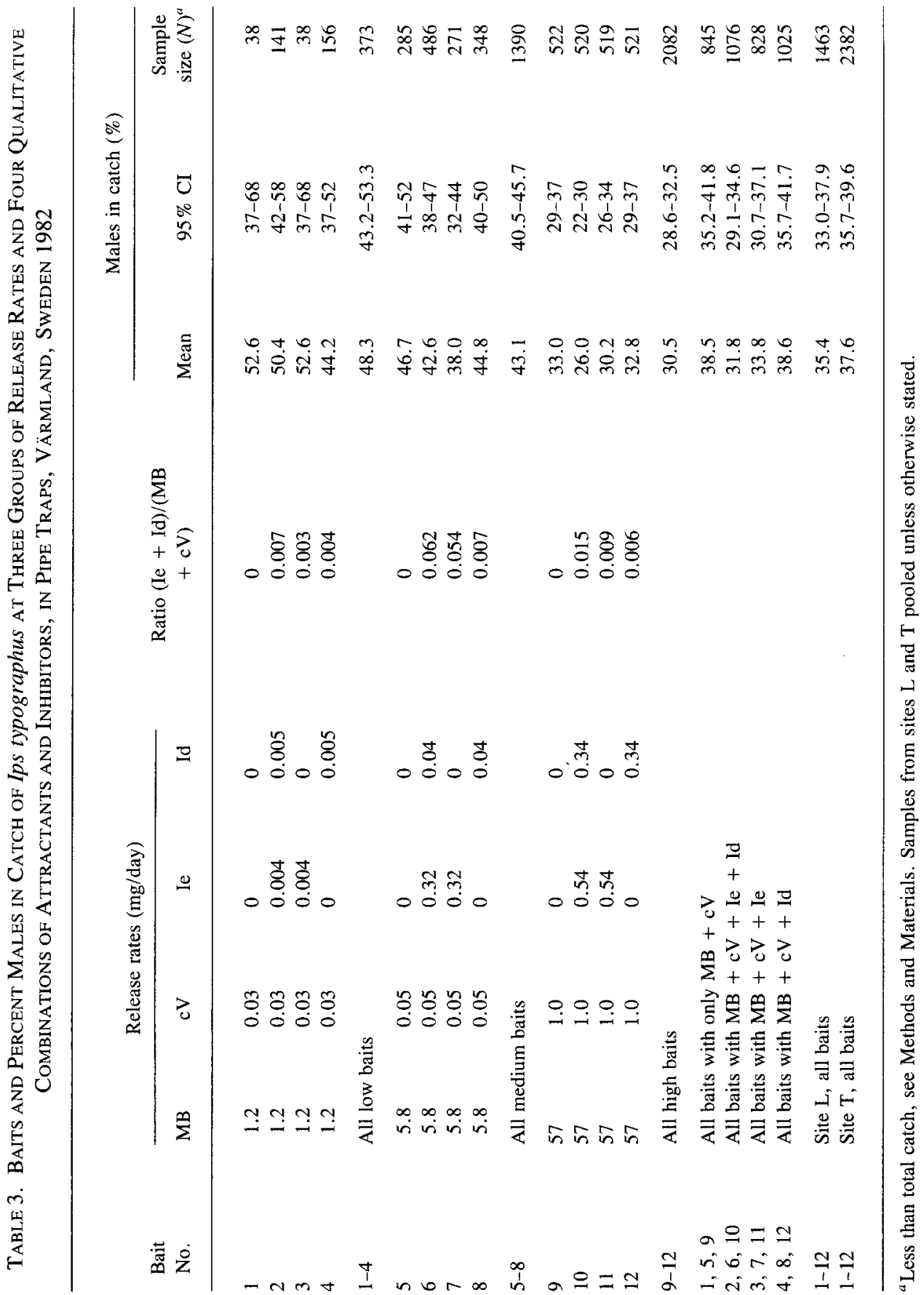


Black pipe traps without exterior funnel ("N 79" in Regnander and Solbreck, 1981) were used in two rows with all spacings $10 \mathrm{~m}$ and randomized in an incomplete Latin-square design, i.e., a bait could occupy a position only once during a test. Two sets each of 10 traps were placed on two 3- to 4-yearold clear-cuts $1.5 \mathrm{~km}$ apart at $50 \mathrm{~m}$ altitude, in Esrum forest distinct, Grib skov, northern Sjaelland, Denmark. The beetle population was judged to be fairly high, with about 100 trees killed within $0.5 \mathrm{~km}$ the year before but none closer to traps than $100 \mathrm{~m}$ at both sites. Trapping was done between May 14 and June 26, 1984.

Statistics. Raw catch data, individual trap catches per replicate (trapping period of one half to several days depending on flight activities), were subjected to a series of transformations, including $\log$, square root, and $\arcsin p^{0.5}$ to achieve homogeneous variances before ANOVA (Sokal and Rohlf, 1981). The transformation which yielded homoscedacity for the catches of each treatment in different experiments, as tested by both Cochran's $C$ and Bartlett-Box tests with $P>5 \%$, along with the highest $F$ ratio was chosen and used in ANOVA and MANOVA on each experiment. All beetles from the sticky traps were sex separated. From pipe traps, 260 beetles (or the whole catch if less than 260) from the total catch of each bait on a site, proportionally sampled from the different replicates over the whole trapping period were separated by sex.

\section{RESULTS}

Attraction to Sources of Attractive Pheromone of Different Quantity at Different Spacings. The ability of the beetles to discriminate between pheromone sources of different strengths and spaced at various "close" distances was studied in the triangle experiment. The beetles discriminated well between pheromone sources of different strengths (Figure 1), the response being highly dependent on the release rates of MB and $\mathrm{cV}$ (Table 2). Even at 3-m spacing, the strongest sources had $65-83 \%$ of the beetles caught by a triangle trap group, while the blank caught only a few percent (Figure 2). There was, however, a significant increase in the catch on the blank with decreasing triangle size, and at $1.5 \mathrm{~m}$ spacing as much as $17 \%$ of the trap group catch was found on the blank trap (Figure 2). Also low and medium release rates had an increased catch at smaller distances when tested in trap groups with a stronger bait present. For the highest release rate, the increase in its proportion of the trap group catch with increased distance was highly significant (Figure 2).

The sex ratios of catch on the blank and low-bait traps were not significantly different from $50 \%$ at 3-, 6-, and 12-m distances (Table 2). The percent males caught was significantly less than $50 \%$ at the highest release rate at all four distances on all eight traps.

Attraction to Pheromone Sources of Different Quantity and Quality at Con- 


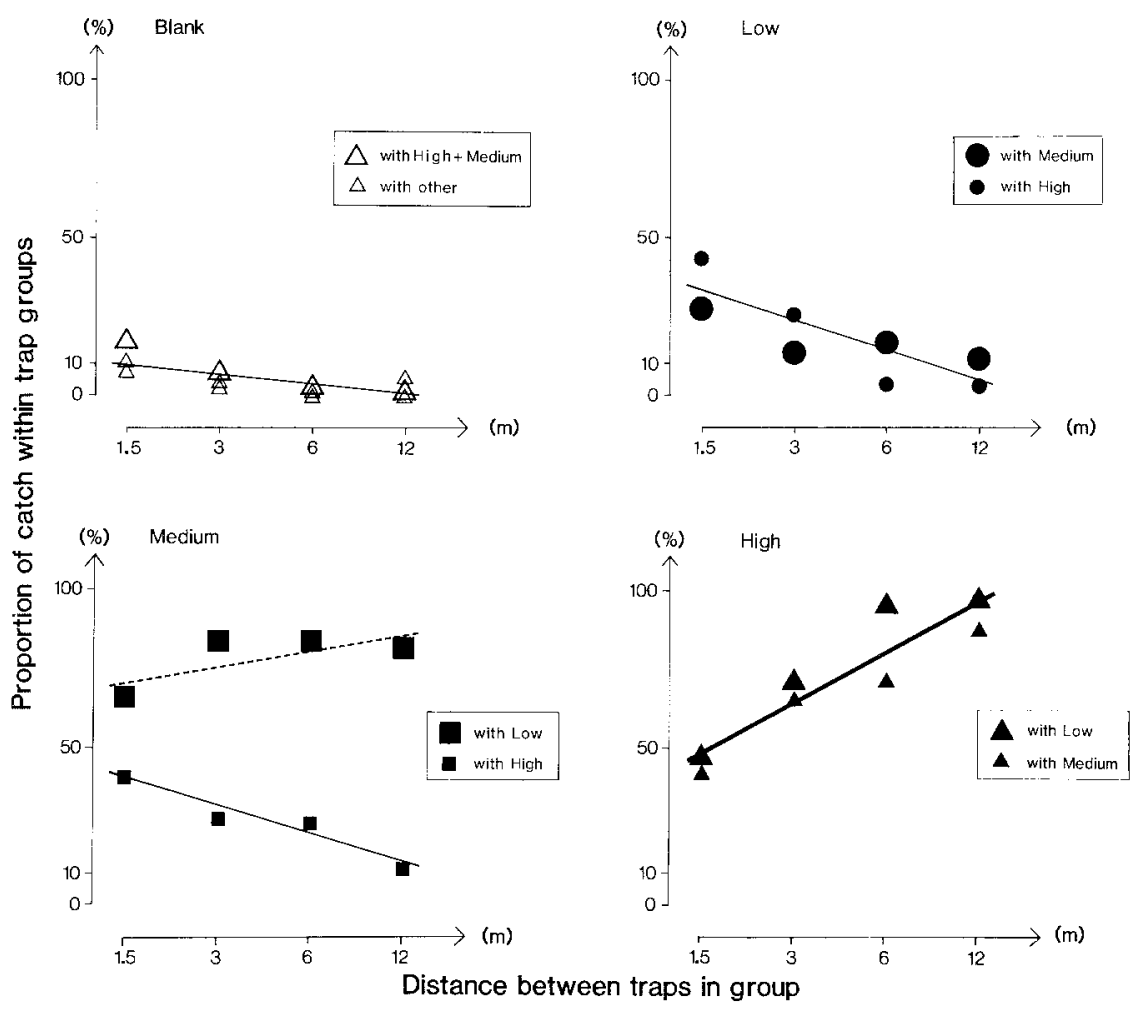

FIG. 2. Relative catches (means) within trap groups as a function of distance between traps. Significance of regression estimated by the slope confidence intervals difference from zero (thick regression line: $P<1 \%$; thin: $P<5 \%$; dotted: $P>5 \%$ ). Combinations not significantly different when only one line is shown. Release rates and sex ratio statistics shown in Table 2.

stant Spacing. I. typographus catch correlated well to three decadic steps in release rates of $\mathrm{MB}+\mathrm{cV}$ from pipe traps spaced $50 \mathrm{~m}$ apart. At the site with a low local beetle population in the 1982 experiment (site L), the catch was directly proportional (slope close to unity) to the quantity of pheromone released (Figure 3). The addition of Ie, Id, or both in combination to these baits at about the same release rates as $\mathrm{cV}$ had very little effect. Multiple ANOVA of the first experiment showed that quantity (amount of $\mathrm{MB}+\mathrm{cV}$ released) had by far the largest $F$ ratio of the main effects. Quality (addition of Ie and/or Id or none) had a smaller but significant effect (Table 4 ). The interactions between quantity and site could be due to the more direct proportionality between bait and response at site L (Figure 3). One-way analysis of variance showed that baits with the same release of $\mathrm{MB}+\mathrm{cV}$ usually formed homogeneous subsets (Figure 4). 


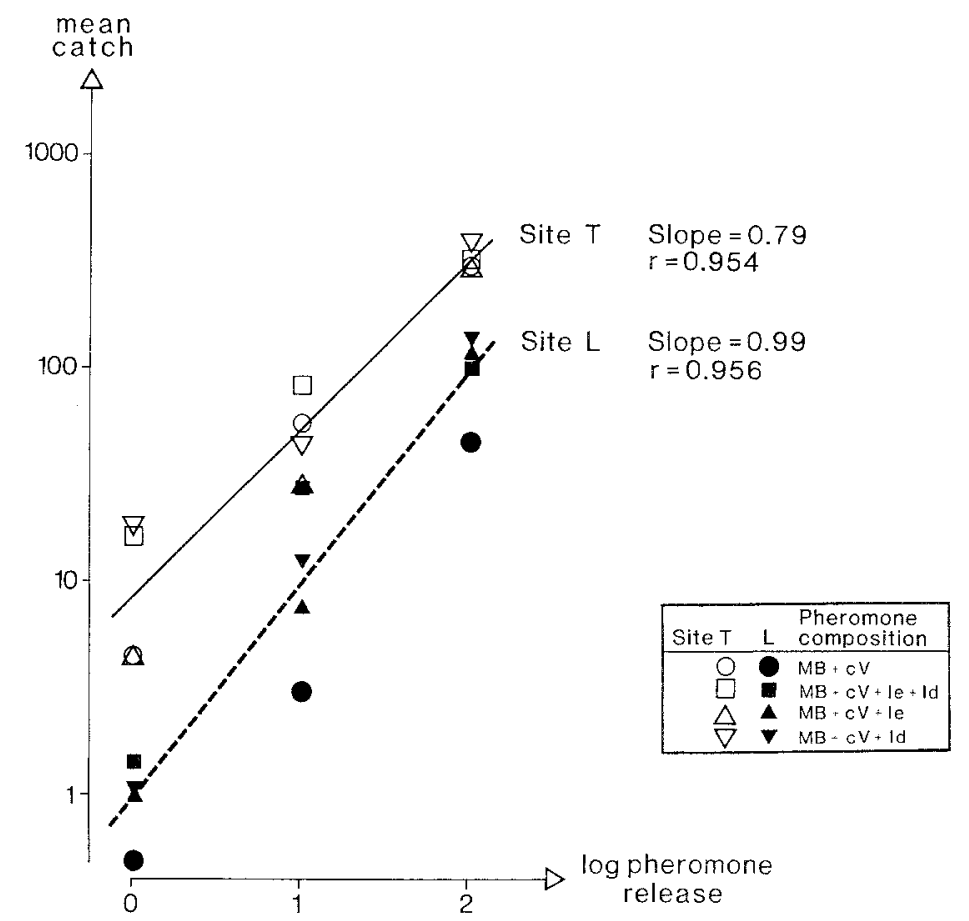

FIG. 3. Dose (log pheromone quantity) and response (untransformed mean trap catches) at sites with a high (T, 8 replicates) and a low (L, 8 replicates) local beetle population. Regression coefficient (slope) different from zero at $P<1 \%$ for both sites. Slope of regression line for site $\mathrm{T}$ significantly different from unity at $P<5 \%$. Release rates of the components (MB, cV, Ie, Id) of qualitatively different baits as shown in Table 3.

For the second experiment (1984) multiple ANOVA showed highly significant first-order effects when Ie, Id, or both were tested with $\mathrm{cV}$ at either $10: 1$ or $0.1: 1$ ratios (Table 4 ). The highest ratio of Ie and the combination Ie + Id, decreased the catch significantly as judged by one-way ANOVA (Figure $5)$. In contrast, the lower amounts of Id, the same as $1: 1$ or a tenth $(0.1: 1)$ that of $\mathrm{cV}$, increased the catch slightly but significantly compared to the control.

Sex Ratios. An increase in bait strength caused a decrease in the proportion of catch that were males from $50 \%$ at the low dose to $30 \%$ at the high dose, similar to the ratios caught in the triangle experiment (Table 3). In fact, at the high bait, the pipe traps and the sticky traps caught an almost identical percentage of males, 32.9 and $33.4 \%$, respectively (Tables 2 and 3 ). The addition of Ie/Id in amounts similar to $\mathrm{cV}$ did not give any significant difference between the sex ratio in the catch of the individual baits in the 1982 experiment. However, the three baits with only $\mathrm{MB}+\mathrm{cV}$ had a higher percentage of males (38.5) than the three baits with both Ie and Id added (31.8\%, Table 3). This 
Table 4. Factorial manova on Effects on Catch in Pipe Traps of Ips typographus of VARIATION OF MB AND cV and AdDITION OF le and Id AT CONSTANT

Ratio, VÄrmland, 1982; AND AdDition of Ie and Id at Different Ratios to CONSTANT MB $+\mathrm{cV}$, GRIB SKOV $1984^{a}$

\begin{tabular}{|c|c|c|c|}
\hline \multirow[t]{2}{*}{ Effects/factor } & \multicolumn{3}{|c|}{ Statistics } \\
\hline & $d f$ & $F$ ratio & $\begin{array}{l}\text { Significance } \\
\text { of } F(\%)\end{array}$ \\
\hline \multicolumn{4}{|c|}{ Different amount of $\mathrm{MB}+\mathrm{cV}$ with Ie and Id added at constant ratio ${ }^{b}$} \\
\hline Within cells & 168 & - & - \\
\hline Constant & 1 & 1276.9 & $<0.1$ \\
\hline \multicolumn{4}{|l|}{ Main effects } \\
\hline Quantity (amount of $\mathrm{MB}+\mathrm{cV}$ ) & 2 & 192.0 & $<0.1$ \\
\hline $\begin{array}{l}\text { Quality (presence of either Ie, Id, } \\
\text { or both or none) }\end{array}$ & 3 & 5.2 & 0.2 \\
\hline Site (study area) & 1 & 132.6 & $<0.1$ \\
\hline \multicolumn{4}{|l|}{ Interactions } \\
\hline Quantity $\times$ site & 2 & 1.9 & 15.8 \\
\hline Quantity $\times$ quality & 6 & 0.7 & 67.0 \\
\hline Quantity $\times$ quality $\times$ site & 6 & 0.7 & 68.0 \\
\hline \multicolumn{4}{|c|}{ Different ratios of $\mathrm{Ie}$ and $\mathrm{Id}$ added to constant amount of $\mathrm{MB}+\mathrm{cV}^{c}$} \\
\hline Within cells & 88 & - & - \\
\hline Constant & 1 & 2851.6 & $<0.1$ \\
\hline \multicolumn{4}{|l|}{ Main effects } \\
\hline Ratio $(\mathrm{Ie}+\mathrm{Id} / \mathrm{MB}+\mathrm{cV})$ & 2 & 25.9 & $<0.1$ \\
\hline $\begin{array}{l}\text { Quality (presence of either Ie, Id, } \\
\text { or both or none) }\end{array}$ & 3 & 36.2 & $<0.1$ \\
\hline Site (study area) & 1 & 0.3 & 59.2 \\
\hline \multicolumn{4}{|l|}{ Interactions } \\
\hline Ratio $\times$ site & 3 & 0.2 & 92.0 \\
\hline Ratio $\times$ quality & 4 & 2.2 & 7.4 \\
\hline Ratio $\times$ quality $\times$ site & 6 & 1.6 & 14.9 \\
\hline
\end{tabular}

${ }^{a}$ For abbreviation of compounds, see Table 1 .

${ }^{b} 1982$ test, 16 replicates, variable analyzed was $\log$ (catch per replicate $+1 / 2$ )

c 1984 test, 11 replicates, variable analyzed was arcsin (proportion of catch per replicate $+1 / 100)^{0.5}$

difference is mainly due to the low male ratio, $26.0 \%$, in the traps with the highest release of $\mathrm{MB}, \mathrm{cV}$, Ie, and Id.

Similarily, in the 1984 experiment, the higher amounts of Ie plus Id added together seemed to reduce the percentage of males (Table 5). However, the sex ratios in 1984 were confounded by a constant decrease in the proportion of males caught during the trapping period. During the nine replicates between May 15 and June 8, the percent males $(y)$ in the total catch fell steadily at about $1 \%$ per day $(x)$, following the regression equation: $y=38.2-1.20 x(r=$ 0.92 , slope different from zero at $P<0.1 \%$ ). A similar trend was noted in 


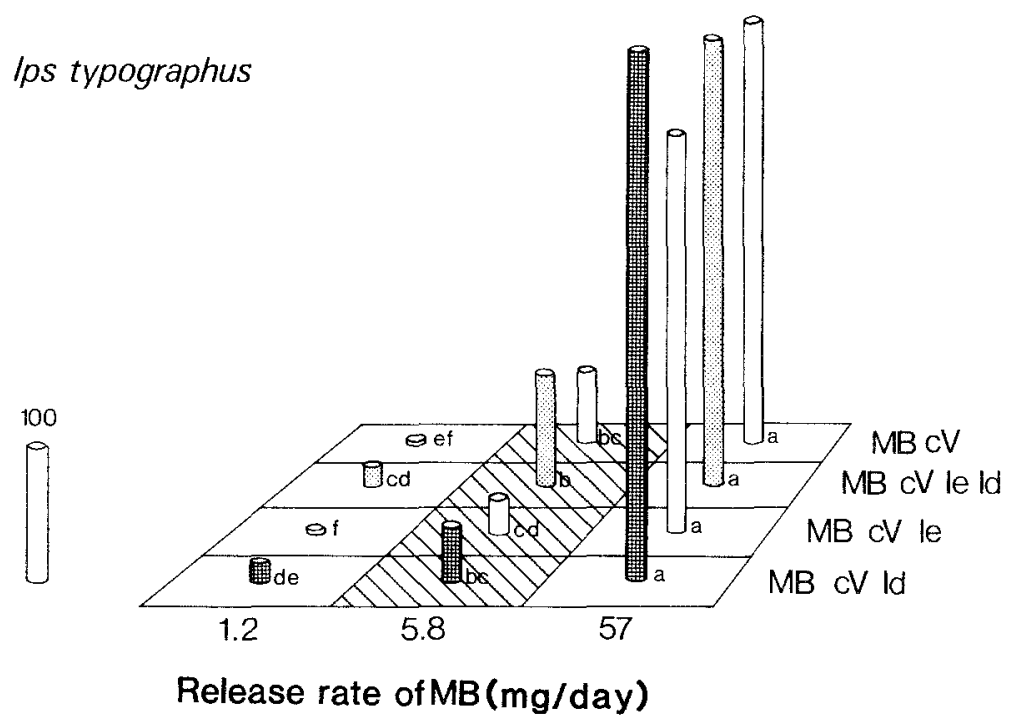

FIG. 4. Response of Ips typographus (untransformed mean catches of 8 replicates) towards quantitative variation of $\mathrm{MB}+\mathrm{cV}$ and addition of Ie and/or Id in well-spaced pipe traps (1982 experiment, site T). Bars with the same letter are not significantly different $[P>5 \%$ by Duncan's multiple range test after ANOVA on catch transformed by $\log ($ catch $+1 / 4)]$. Squares with parallel hatching contain baits used in both 1982 and 1984 experiments. Bars with stippled hatching indicate baits with both Ie and Id added, while cross-hatching indicates addition of Id. Sex ratio statistics and release rates are shown in Table 3.

Ips typographus

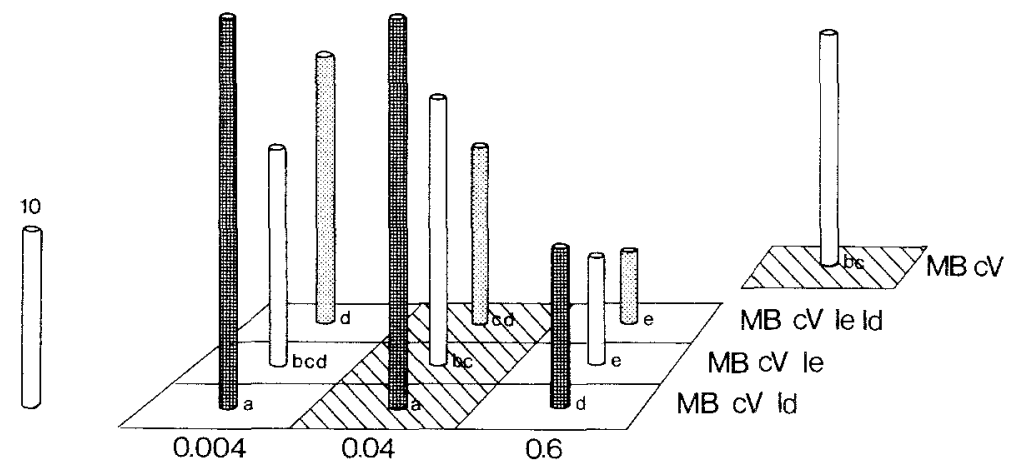

Release rate of le/Id (mg/day) added to MB cV

FIG. 5. Response of Ips typographus (untransformed means) to addition of Ie and/or Id (1984 experiment, 11 replicates, two sites pooled) to $\mathrm{MB}+\mathrm{cV}$ at $5.8+0.05 \mathrm{mg} /$ day. Statistics and hatchings as in Figure 4, except that arcsin (proportion of catch per replicate $+1 / 100)^{0.5}$ was used in ANOVA. 


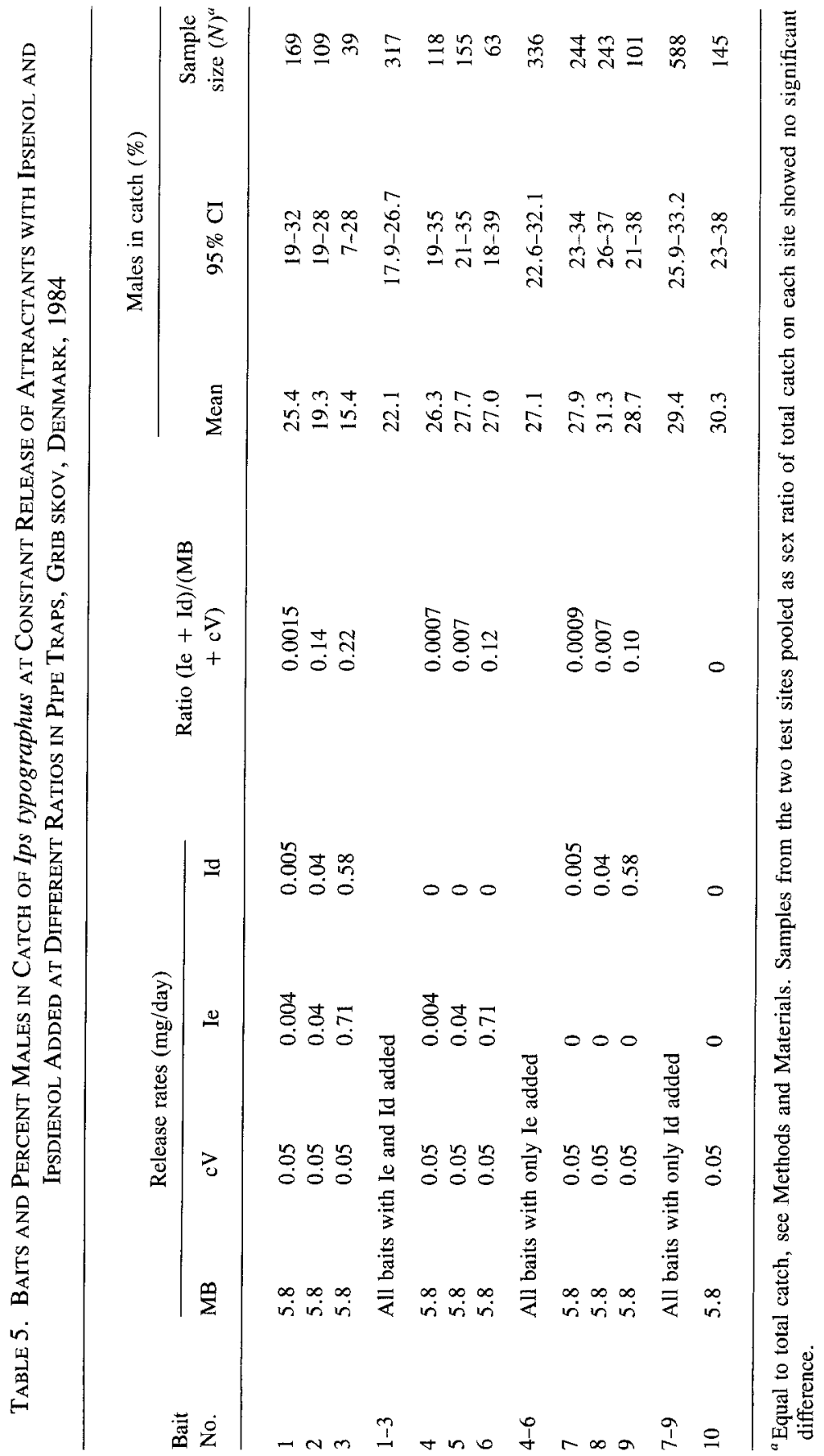




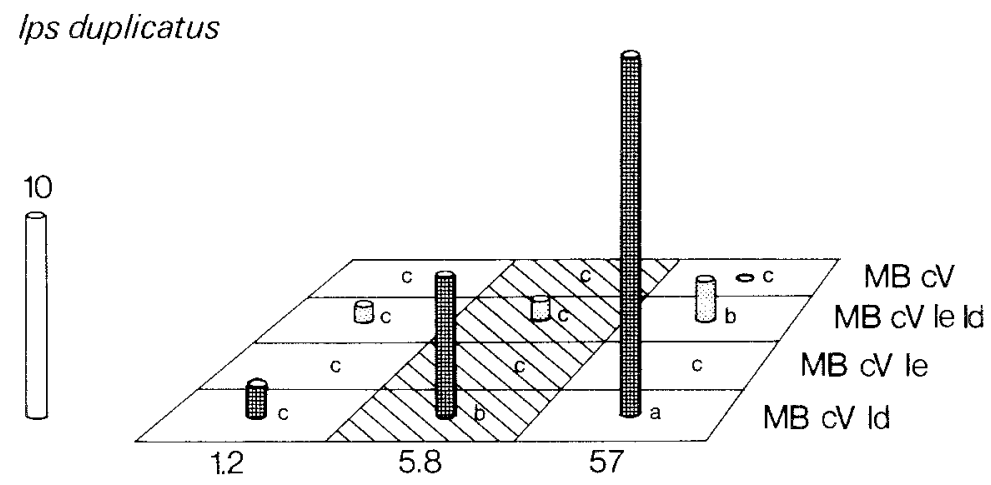

Thanasimus formicarius
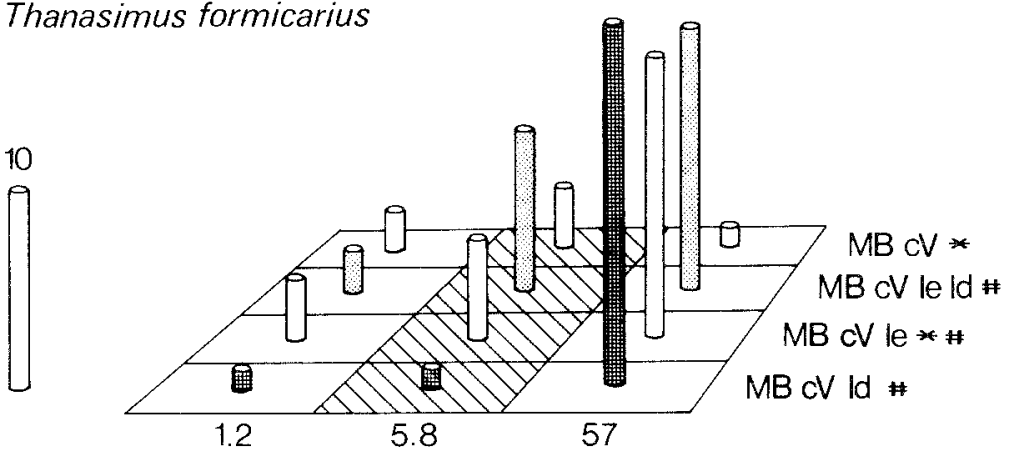

Release rate of MB ( $\mathrm{mg} /$ day)

FIG. 6. Response of $I$. duplicatus (untransformed mean catches) in 1982 experiment, sites pooled. Statistics and hatchings as in Figure 4. Response of Thanasimus formicarius (total sums caught, sites pooled) in 1982 experiment. Hatching as in Figure 4. Qualitative bait combinations followed by the same symbol $(*, H)$ are not significantly different ( $P>5 \%$, Wilcoxon matched-pairs signed-ranks test).

1982 in Värmland, but the smaller number of replicates during this period makes a statistical analysis less valid.

Other Species. In contrast to I. typographus, I. duplicatus (Sahlb.) did not react to a change in $\mathrm{MB}+\mathrm{cV}$ release, but responded only to addition of Id and/or Ie and was attracted strongly only to baits containing high levels of Id (Figure 6). Inclusion of Ie reduced the catch clearly and significantly at all release rates. The predator Thanasimus formicarius (L.) (Coleoptera: Cleridae) was attracted predominantly towards baits with high amounts of Ie and/or Id (Figure 6). The smaller predator T. femoralis (Zett.) was attracted in a similar pattern but in very small numbers. 


\section{DISCUSSION}

Methodology and its Relationship to Natural Behavior. In order to arrive at meaningful biological interpretations of results from trapping with synthetic compounds, three elements of the methods must be scrutinized in particular: trap design, purity of chemicals, and release rates of chemicals.

The traps used in this study were either a sticky trap with silhouette, which require beetles to land in order to be trapped, or pipe traps with holes which require a beetle both to land and enter a hole to be trapped. Thus, both trap types reflect the landing rate, which is one of the most important parameters in the host colonization process (Byers et al., 1984). The two trap types also had very similar sex ratios in their catches, both here and in a parallel study (Schlyter et al., 1987a).

The chemicals used in this study were all of fairly high chemical purity (Table 1), and the $\mathrm{cV}$ was of correct $(>94 \% S$ ) enantiomeric composition while Ie and Id were racemic $(50 / 50 R / S)$. The natural composition of Ie and Id in $I$. typographus is probably not racemic (Francke et al., 1980). Attractive synergistic properties of these compounds could thus have been concealed by the presence of an unnatural enantiomer (Wood, 1982; Vité et al., 1985). Possible inhibitory properties of a compound might also be hidden by an incorrect enantiomeric composition.

The release rates of the different pheromone components are very critical in a study of this kind, because they must ultimately be compared to natural pheromone sources. It is difficult to determine the actual release rate during attraction in the field and so we must rely on laboratory estimates until further studies are done (see Table 1). I. typographus màles produce high amounts of MB when initiating the nuptial chamber, while production of $\mathrm{cV}$ is dependent on the amount and enantiomeric composition (optical purity) of $\alpha$-pinene in the bark (Birgersson et al., 1984; unpublished). For males attacking a resin-rich standing tree, the release of $\mathrm{MB}$ and $\mathrm{cV}$ per male has been estimated by air entrainments to be on the average about $100 \mu \mathrm{g} /$ day and $1-2 \mu \mathrm{g} / \mathrm{day}$, respectively, per male (Schlyter et al., 1987b; Birgersson et al., unpublished). Typically, as more than 1000 males might attack a standing tree, this would yield a release of at least $100 \mathrm{mg} /$ day of $\mathrm{MB}$ and $1-2 \mathrm{mg} /$ day of $\mathrm{cV}$ per tree, which corresponds to the highest dose used per trap in the present study.

Quantitative Hypothesis. There was a dramatic effect on the response of $I$. typographus with a change in dose of attractive pheromone components. In two of three sites the catch was directly proportional to the release rate. This finding is in contrast to the generally held concept that in pheromone studies one usually gets only a doubled response with a 10 -fold increase in dose. The nearly proportional relationship could be related to the MB component of the pheromone, which has an unusually steep dose-response curve both in EAGs and in field tests (Dickens, 1981; Schlyter et al., 1987a). The beetles were able to differ- 
entiate between pheromone sources of different strengths only $1.5 \mathrm{~m}$ apart. This indicates they can sense which area is likely to provide the better habitat in terms of avoiding competition. However, "low" attractant releasing areas could not be identified as either a beginning or terminating colonization site based on the quantitative hypothesis alone.

The almost equal sex ratio obtained both on sticky traps and in pipe traps with the low releasing baits as compared to female biased sex ratios on higher releasing baits indicates that an area with low numbers of males in the earliest attack phases, producing a weak pheromone signal (Figure 7A, B), would then attract relatively more males and result in a mass attack (Figure 7C).

The nearly equal sex ratio obtained on weak baits in pipe traps with funnel in our study indicates that the low proportion of males always found in pipe traps in mass trapping (Bakke et al., 1983) is not only due to an intrinsic property of the pipe traps, but is mainly due to the high pheromone doses used. Males are proportionally less attracted to strong pheromone sources than females. They may well be deflected from a strong pheromone source, such as a tree under mass attack (Figure 7C,D) and start colonization in a patch with lower amounts of pheromone (Byers, 1983). In a Y-tube walking bioassay, Schlyter and Löfqvist (1986) showed that females chose stronger sources of natural male pheromone more often than males did. At a strong pheromone source, flying males may reach a threshold concentration releasing landing or avoidance further away than at a weaker source. The reason for the sexual differences could then be that, although both sexes are equally attracted from a distance (Schlyter et al., 1987a), males are physiologically more sensitive to the pheromone (Dickens, 1981). Males might respond further away than females by entering the "landing step" in the attraction sequence and so land in less populated areas and expand the colonization area (Schlyter et al., 1987a).

The quantitative mechanism, if invoked alone, would predict that males be attracted to completely colonized trees (where all males are mated, Figure $7 \mathrm{E}$ ) with a low release of attractive pheromone, something which would be nonadaptive.

Qualitative Hypothesis. Males could separate a new and weak pheromone source from an old and weak source of $\mathrm{MB}$ and $\mathrm{cV}$ by the release of $\mathrm{Id}$ and Ie from the older source. More specifically, it could be of interest for a male to assess the ratio of Ie and Id to $\mathrm{MB}$ and $\mathrm{cV}$. Addition of $\mathrm{Ie}$ and Id in the same quantity as $\mathrm{cV}(\mathrm{Ie}+\mathrm{Id}: \mathrm{cV}=0.9: 1)$ had no effect in the 1982 test, even at the high release rate $(0.9 \mathrm{mg} / \mathrm{day})$. When these compounds were added in the 1984 test at approximately the same release rate $(1.3 \mathrm{mg} /$ day $)$, but at a much higher ratio to $\mathrm{cV}(25: 1)$, a clear reduction in catch resulted.

As reported by Bakke (1975), the competitor I. duplicatus is strongly attracted to baits containing Id, and this was also shown in our test in Värmland (species not present in Denmark). I. duplicatus was also inhibited by le at much lower doses than I. typographus, an effect also found in Norway (Bakke, per- 


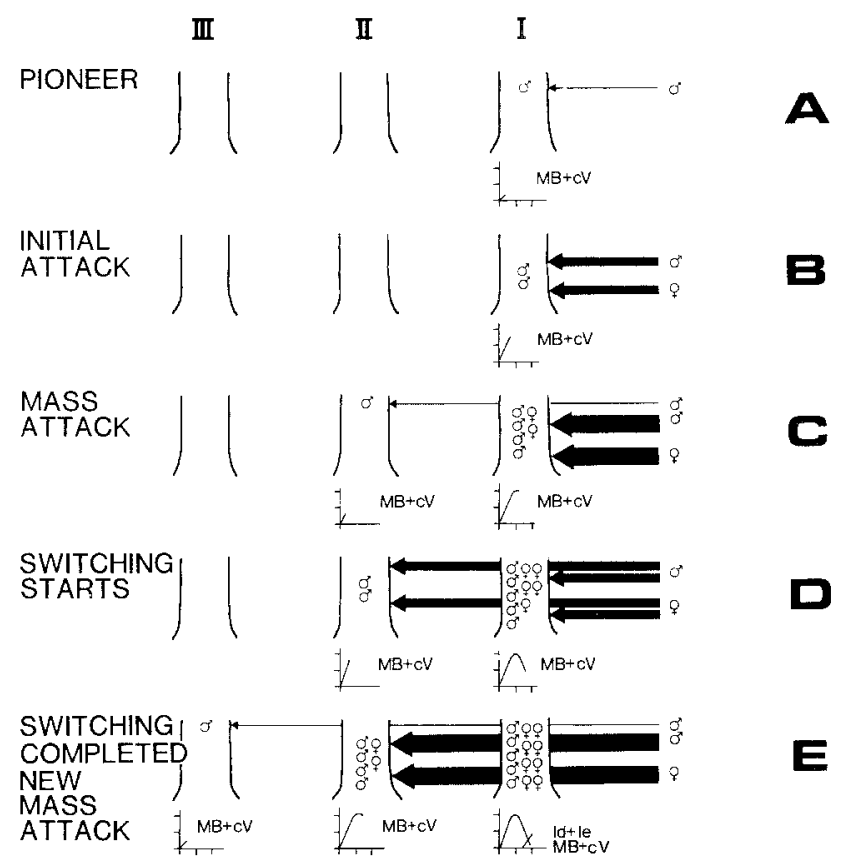

FIG. 7. (A) At the low densities in the pioneer stage, density is increased by recruiting more beetles by the increased release of aggregation pheromone $(\mathrm{MB}+\mathrm{cV})$. (B) If the first pioneering males are not killed by the resin flow in a short time (hours-1 day), they will produce large amounts of pheromone, and if the beetle population is high, the attracted beetles will start an initial attack to exhaust the defensive resin flow. (C) In the mass attack phase the tree (I) is taken over, and large numbers of females and males are attracted. A small proportion of males are deflected and land on an adjacent tree (II). (D) While attraction declines towards the first tree as a result of the decline in production of attractive pheromone components, attraction increases towards the second tree, which starts a switch in attraction. (E) The first "switching" is now completed as very few beetles are attracted to the first tree, which now produces only small amounts of attractants $(\mathrm{MB}+\mathrm{cV})$ but increasing amounts of inhibitory compounds (Ie + Id and others). The second tree (II) has now become the focus of attraction, where a new mass attack starts, while a small fraction of males again is deflected and lands on a third tree (III). At high population levels, this kind of density regulation behavior could mean the death of hundreds or thousands of standing trees, while at lower normal population levels, the colonization may proceed only along patches on a single fallen tree. The small graphs under tree trunks represent log pheromone release and are a simplification and condensation of Figures 3 and 4 in Birgersson et al. (1984). The marks on the $x$ axis represent the attack phases 1,3 , and 6 , corresponding to males boring in cortex bark (1), having completed nuptial chamber (3), and being joined by egg-laying females (6). 
sonal communication). As I. duplicatus is the weaker competitor for breeding substrate when attacking at the same time as I. typographus (Anderbrant and Schlyter, unpublished), it is surprising that $I$. duplicatus is attracted to a blend of chemicals (MB, cV, and Id) produced by I. typographus in an already colonized patch. This question can probably not be resolved before we gain a better understanding of the quantity and chirality of Id and Ie produced by these two competing species in different phases.

The two Thanasimus species were little attracted to baits with $\mathrm{MB}$ and $\mathrm{cV}$, but baits with addition of Ie and Id were attractive kairomone sources, which corresponds well to the results of Bakke and Kvamme (1981).

Addition of Id alone showed an interesting effect on I. typographus: at low release rates and proportions $(0.1: 1$ and $0.8: 1$ of $\mathrm{Id}$ to $\mathrm{cV})$ it increased the catch somewhat, while at the higher rate $(12: 1 . \mathrm{Id}: \mathrm{cV})$ it decreased the catch (Figure 5). This multifunctional (Rudinsky, 1973) effect of Id is not shared by Ie, which seems to decrease attraction in all baits where it is added alone (Figures 4 and 5). The reason for this difference between the compounds might be that Id is produced somewhat earlier than Ie (Birgersson et al., 1984; unpublished). Verbenone, reported by Bakke (1981) as an inhibitor of trap catches and often produced in considerable quantities in galleries in later phases (Leufvén and Birgersson, 1987) could also contribute to the message of an "old patch."

Other means of communication than pheromonal, such as acoustic, could also affect the colonization density by producing spacing patterns (Byers, 1984). However, the stridulation in I. typographus is of low amplitude (Rudinsky, 1979) and would result in a short communication distance (millimeters-centimeters) and could contribute little directly to the switching between patches of the scale discussed here.

Conclusion. Using the chemical data from Birgersson et al. (1984), biological data from Schlyter and Löfqvist (1986), and this study, we propose a combined hypothesis in a graphic model of how attack density could be regulated by the aggregation switching to other trees (areas) at a high population level, as shown in Figure 7. The switching is effected by both the quantitative and qualitative mechanisms acting in sequence. A high quantity of $\mathrm{MB}$ and $\mathrm{cV}$ is the mass attack signal and also enlarges the area of attack as many of the males land on adjacent trees. The aggregation switching to new areas or trees is completed by a decrease of $\mathrm{MB}$ and $\mathrm{cV}$ in combination with an increase of the proportion of Id and Ie and possibly other later-occurring substances at the initial colonization area.

Acknowledgments-Chemicals (cV, Id, and Ie) were provided by Borregaard, Sarpsborg (L. Riege) and $\mathrm{cV}$ was purified by P. Baeckström, KTH, Stockholm. Study areas were generously supplied by Billerud (M. Sjölander) and valuable field information by Skogsvardsstyrelsen (I. Olsson) 1982 in Torsby, Sweden. Statskovvesenet in Grib skov, Esrum forest district, Denmark. provided the 1984 study areas which were located with the help of H.P. Ravn, Landbohøjskolen, 
Copenhagen. Dedicated field assistance was given by E.V. Jirle, M. Appelgren, G. Birgersson, E. Marling, and K. Persson. The extensive effort of sample preparation and measurements of dispensers was done by E. Marling, B. Bartosch, J. Börnfors, and E. Wijk. The mini wind tunnel was designed and built by J. Jönsson. The drawings were made by E.V. Jirle. We thank them all for their professional help and commitment.

Funding was provided by Swedish Research councils (NFR, FRN, SJFR, STU).

\section{REFERENCES}

AndERBRANT, O. 1986. A model for the temperature and density dependent reemergence of the bark beetle Ips typographus. Entomol. Exp. Appl. 40:81-88.

Anderbrant, O., SChlyter, F., and Birgersson, G. 1985. Intraspecific competition affecting parents and offspring in the bark beetle Ips typographus. Oikos 45:89-98.

ALCOCK, J. 1982. Natural selection and communication among bark beetles. Fla Entomol. 65:1732.

BAKKE, A. 1975. Aggregation pheromone in the bark beetle, Ips duplicatus (Sahlberg). Norw. J. Entomol. 22:67-69.

BAKKE, A. 1981. Inhibition of the response in Ips typographus to the aggregation pheromone; field evaluation of verbenone and ipsenol. Z. Angew. Entomol. 92:172-177.

BaKke, A., and Kvamme, T. 1981. Kairomone response on Thanasimus predators to pheromone components of Ips typographus. J. Chem. Ecol. 7:305-312.

BAKKE, A., and RIEGE, L. 1982. The pheromone of the spruce bark beetle Ips typographus and its potential use in the suppression of beetle populations, pp. 3-15, in A.F. Kydonieus and M. Beroza (eds.). Insect Suppression with Controlled Release Pheromone Systems, Vol. II. CRC Press, Boca Raton, Florida.

Bakke, A., Fr $\phi$ Yen, P., and Skatteb $\phi$ L, L. 1977. Field response to a new pheromonal compound isolated from Ips typographus. Naturwissenschaften 64:98.

Bakke, A., SaEther, T., and Kvamme, T. 1983. Mass trapping of the spruce bark beetle Ips typographus. Pheromone and trap technology. Medd. Nor. Inst. Skogforsk. 38(3):1-35.

Birgersson, G., SCHLYTER, F., LÖFQVist, J., and Bergström, G. 1984. Quantitative variation of pheromone components in the spruce bark beetle Ips typographus from different attack phases. J. Chem. Ecol. 10:1029-1055.

BotTERWEG, P.F. 1983. The effect of attack density on size, fat content and emergence of the spruce bark beetle Ips typographus (L.). Z. Angew. Entomol. 96:47-55.

BYERS, J.A. 1983. Sex specific responses to aggregation pheromone: Regulation of colonization density in the bark beetle Ips paraconfusus. J. Chem. Ecol. 9:129-142.

BYERS, J.A. 1984. Nearest-neighbor analysis and simulation of distribution patterns indicates an attack spacing mechanism in the bark beetle, Ips typographus (Coleoptera: Scolytidae). Environ. Entomol. 9:1191-1200.

Byers, J.A., WoOd, D.L., Craig, J., and Hendry, L.B. 1984. Attractive and inhibitory pheromones produced in the bark beetle, Dendroctonus brevicomis, during host colonization: Regulation of inter- and intraspecific competition. J. Chem. Ecol. 10:861-877.

Coulson, R.N. 1979. Population dynamics of bark beetles. Annu. Rev. Entomol. 24:417-447.

DICKENS, J.C. 1981. Behavioral and electrophysiological responses of the bark beetle, Ips typographus, to potential pheromone components. Physiol. Entomol. 6:251-261.

Francke, W., Sauerwein, P., Vité, J.P., and Klimetzek, D. 1980. The pheromone bouquet of Ips amitinus. Naturwissenschaften 67:147-148.

Geiszler, D. R., GalluCCI, V.F., and Gara, R.I. 1980. Modeling the dynamics of mountain pine beetle aggregation in a lodgepole pine. Oecologia 46:244-253. 
LEKANDER, B. 1972. A massoutbreak of Ips typographus in Gästrikland, central Sweden, in 19451952. Department of Forest Zoology, Royal College of Forestry, Research Notes No. 10 (in Swedish with English summary). $38 \mathrm{pp}$.

LEUFVÉN, A., and BIRGERSSON, G. 1987. Quantitative variation of different monoterpenes around galleries of Ips typographus (Coleoptera: Scolytidae) attacking Norway spruce. Can. J. Bot. 65 (in press).

REgnander, J., and SOLBRECK, C. 1981. Effectiveness of different types of pheromone traps used against Ips typographus (L.) (Col., Scolytidae) in Sweden. Anz. Schaedlingskde. Pflanz. Umweltschutz 54:104-108.

RUDINSKY, J.A. 1973. Multiple functions of the southern pine beetle pheromone verbenone. Environ. Entomol. 2:511-514.

RUdinsky, J.A. 1979. Chemoacoustically induced behavior of Ips typographus (Col.: Scolytidae). Z. Angew. Entomol. 88:537-541.

SeHLYTER, F., and LÖFQVIST, J. 1986. Response of walking spruce bark beetles Ips typographus (L.) to natural pheromone from different attack phases. Entomol. Exp. Appl. 41:219-230.

SCHLYTER, F., LÖFQVIST, J., and BYERS, J.A. 1987a. The behavioral sequence in attraction to pheromone sources in the bark beetle Ips typographus. Physiol. Entomol. 12 (in press).

SChlyter, F., Birgersson, G., Byers, J.A., Löfqvist, J., and Bergström, G. 1987b. Field response of the spruce bark beetle, Ips typographus to aggregation pheromone candidates. $J$. Chem. Ecol. 13:706-716.

SOKAL, R., and RoHLF, F. 1981. Biometry. W.H. Freeman, San Francisco.

VitÉ, J.P., Billings, R.F., WARE, C.W., and MORI, K. 1985. Southern pine beetle: Enhancement or inhibition of aggregation response mediated by enantiomers of endo-brevicomin. Naturwissenschaften 72:99-100.

Thalenhorst, W. 1958. Grundzüge der Populationsdynamik der grossen Fichtenborkäfer Ips typographus L. Schriftenr. Forstl. Fak. Univ. Goettingen 21:1-126.

WOOD, D. 1982. The role of pheromones, kairomones, and allomones in the host selection and colonization behavior of bark beetles. Annu. Rev. Entomol. 27:411-446. 